\title{
Community-Based Primary Healthcare Training for Physiotherapy Undergraduates: Perceptions of Physiotherapy Academics
}

\author{
Geneshree Govender ${ }^{1}$, Nomzamo Chemane ${ }^{1}$, Saul Cobbing ${ }^{1} \&$ Verusia Chetty ${ }^{1}$ \\ ${ }^{1}$ Discipline of Physiotherapy, School of Health Sciences, Westville Campus, University of KwaZulu-Natal, \\ Durban, South Africa \\ Correspondence: Verusia Chetty, Discipline of Physiotherapy, School of Health Sciences, Westville Campus, \\ University of KwaZulu-Natal, Private Bag X54001, Durban, 4000, South Africa. Tel: 27-31-748-905-279. E-mail: \\ chettyve@ukzn.ac.za
}

Received: June 24, 2018 Accepted: August 2, 2018 Online Published: November 12, 2018

doi:10.5539/gjhs.v10n12p75

URL: https://doi.org/10.5539/gjhs.v10n12p75

\begin{abstract}
Community-based primary healthcare training for health science students is based on the tenets of primary healthcare. The approach seeks to provide clinical education and training for health science students in previously disenfranchised communities. Some South African universities train their physiotherapy students through a community-based primary healthcare approach to undergraduate training. However, there is currently a lack of an integrated model guiding clinical education for physiotherapy clinical education in the country. The aim of this paper was to explore the perceptions of physiotherapy academics about a novel, community-based primary healthcare approach to clinical education for students at a university in South Africa. This study sought to inform the roll-out of an evidence-based model for physiotherapy education. A qualitative explorative approach, using semi-structured interviews with physiotherapy academics at the institution, was used to explore their perceptions of the community-based primary healthcare training platform. Data was analysed using conventional content analysis and was classified into themes and sub-themes. Four overarching themes emerged, namely: curriculum review, constraints to decentralised learning, benefits of community-based clinical education and recommendations for the learning platform. Participating academics believed that community-based primary healthcare training is an approach that influences students to be socially responsive, while providing access to healthcare services, such as rehabilitation, in resource-poor communities in South Africa.
\end{abstract}

Keywords: community-based primary healthcare, physiotherapy, clinical education

\section{Introduction}

In KwaZulu-Natal, an eastern coastal province in South Africa, many people live in previously disenfranchised rural and resource-poor communities, with poor access to healthcare. Healthcare professionals in South Africa should be prepared to offer care to people living in such conditions. However, healthcare facilities in rural communities experience a shortage of staff, coupled with poor infrastructure. Added challenges exist with regards to recruitment and retention of healthcare staff; linked to inadequate funding (Wilson et al., 2009). A core goal of any healthcare system is to offer seamless care to improve health outcomes through the adequate provision of clinical and public health services (Panda \& Thakur, 2016). However, in South Africa, the public healthcare sector suffers from a lack of resources; while the private healthcare sector is comparatively over-serviced. It is recognised that a shift is needed in the healthcare system to remedy the disparity. The South African government is attempting to address these disparities through the adoption of National Health Insurance (NHI), which seeks to improve access to healthcare through a primary healthcare approach, ensuring care within, and closer to, communities that were previously marginalised (South African Government, 2015).

In an attempt to prepare undergraduate health science students for this shift in healthcare, the University of KwaZulu-Natal (UKZN) in South Africa and the local Department of Health agreed on a community-based primary healthcare approach to the training of undergraduate students. Community-based primary healthcare training, which is based on the tenets of primary healthcare (Kautzky \& Tollman, 2008), offers a chance for undergraduate students, such as physiotherapists, to be adequately equipped for the communities they will serve. Students are placed in rural and peri-urban communities for clinical and service learning in order to acquire the necessary core competencies and to develop the social responsiveness essential for healthcare practice. This is 
coupled with traditional clinical education through patient management. Although the community-based primary healthcare approach is sound, there is no model that guides the roll-out of this novel approach. This led to a group of researchers proposing the development of an integrated model for the community-based primary healthcare approach to clinical education for the health sciences at the University of KwaZulu-Natal (Govender et al., 2018). This paper specifically aimed at exploring the perceptions of the academic staff about the community-based primary healthcare training approach adopted by the discipline of physiotherapy, in order to inform the overarching model of clinical education for health science students at a South African university (Govender et al., 2018).

\section{Methodology}

A qualitative descriptive explorative approach was used to gain insight into the perceptions of academic staff at a tertiary institution in South Africa, about a community-based primary healthcare training framework for undergraduate physiotherapy students (Elliott \& Timulak, 2005). Given the novelty of this approach, an exploration of real-life experiences of academics involved in the clinical education of undergraduate physiotherapy students in a resource-limited, higher education context was deemed suitable for this study (Creswell \& Poth, 2017). The community-based primary healthcare training framework will be referred to as the decentralised clinical training (DCT) platform from this point on.

\subsection{Participants}

Eight academics from the physiotherapy department at UKZN were purposively selected due to their involvement in the clinical training platform for the undergraduate programme. They were all qualified physiotherapists, registered with the Health Professionals Council of South Africa, and employed on a full-time basis by the university.

\subsection{Data Collection}

Once ethical clearance had been obtained from the Humanities and Social Sciences Research Ethics Committee at the university, and informed consent had been obtained from the participants, semi-structured interviews were conducted (Longhurst, 2003). The interviews were held in the physiotherapy department seminar room at the end of the first year of implementation of the DCT platform Anonymity was maintained through the use of pseudonyms when reflecting the results or discussing the findings of the study. Each interview was recorded and lasted between 45 minutes and one hour, with both a researcher and moderator experienced in qualitative methods being present. Interviews were conducted in English and non-verbal nuances were noted by the moderator.

\subsection{Data Analysis}

Following the interview process, the recorded data was then transcribed verbatim. The audio recordings were listened to several times to eliminate any errors during transcription. The transcribed data was read and re-read for familiarisation and to acquire in-depth understanding of the data and emerging themes. Both the researcher and moderator executed data coding using conventional content analysis, reaching a consensus on the overarching themes and sub-themes. The most salient quotes were selected for this paper, to provide examples of the rich descriptions in the interviews.

\section{Results}

Details of the eight academic participants are captured in Table 1, using pseudonyms to protect the identity of faculty members. Three academics had less than 10 years of academic clinical teaching experience; while two had more than 20 years of experience. Six of the staff were aged between of 30 and 40 and two were over 50 years of age. 
Table 1. Characteristics of physiotherapy academics

\begin{tabular}{|c|c|c|c|c|}
\hline $\begin{array}{l}\text { Participant } \\
\text { Pseudonym }\end{array}$ & Age & Gender & $\begin{array}{l}\text { Years of academic clinical } \\
\text { experience }\end{array}$ & Area of expertise \\
\hline Vani & $30-40$ & $F$ & 12 years & Neurology/Community \\
\hline Sam & $30-40$ & $\mathrm{~F}$ & 10 years & Cardiopulmonary \\
\hline Neville & $30-40$ & M & 17 years & Neurology/Community \\
\hline Zinhle & $30-40$ & $\mathrm{~F}$ & 2 years & Neurology/Community \\
\hline Tina & $51-60$ & $\mathrm{~F}$ & 33 years & Neurology/Community \\
\hline Selvan & $51-60$ & M & 20 years & Orthopaedics \\
\hline Simon & $30-40$ & M & 7 years & Cardiopulmonary \\
\hline Rod & $30-40$ & M & 8 years & Orthopaedics \\
\hline
\end{tabular}

The interview data yielded four overarching themes, namely: curriculum review, constraints to decentralised learning, benefits of community-based clinical education and recommendations for a learning platform. Table 2 reflects the themes and sub-themes from the interviews with the physiotherapy academics.

Table 2. Summary of Themes and sub-themes

\begin{tabular}{ll}
\hline Themes & Sub-themes \\
\hline Curriculum review & Student-led teaching approach \\
& Pre-clinical education \\
& Integration of theory into clinical practice \\
& Strengths in the programme \\
\hline Constraints to decentralised learning & Gaps in the programme \\
\hline Benefits of community-based clinical education & Resource limitations \\
& Partnership parody \\
& Lack of supervision \\
\hline Recommendations for learning platform & Personal growth for students \\
& Personal growth for academics \\
\hline & Community as teachers \\
\hline
\end{tabular}

The theme curriculum review encompassed the sub-themes: student-led teaching approach; pre-clinical education; integration of theory into clinical practice; strengths in the programme; and gaps in the programme. Staff identified strengths in the curriculum with a shift to student-led independent learning.

One academic commented: "I think that maybe if we move away from teacher-directed, towards a more student-led learning, it would be ideal; so I think even for me today to give you the answer (referring to whether the community-based primary healthcare training works) would mean that it's coming from a teacher-led approach" (Neville). The academic believed that it was important to shift toward a student-centred teaching approach.

Another academic noted: "Clinical training, for one, will allow them the opportunity to be involved and further supplement the clinical education of the student following the preparation they received at varsity" (Sam). The pre-clinical training that is offered at the university was seen as an adjunct to clinical practice received on the DCT 
platforms.

Many of the academics echoed the sentiments of Zinhle who said, "I think for me, its exposure and really trying to integrate theory with practice". The staff felt that the DCT would afford students the opportunity to integrate their theoretical foundation into good clinical practice.

Tina said, "I think there are modules within the undergraduate programme that are equipping students for this training framework from first year up to final year"; and Neville felt: "This model definitely facilitates independent learning and that in itself will predispose them to become lifelong learners".

Staff also felt that the curriculum needed review in some areas. Vani said, "I think we need to look at the UKZN core competency framework," and continued to allude to the fact that it is not emphasised in the programme. Simon also highlighted that the "improvement of the curriculum to include socially responsible graduates" was important for preparation for the DCT platform. The pre-clinical teaching was believed to be hurried, as voiced by Rod who said, "We had to speed up all our teaching".

The theme constraints to decentralised learning included the sub-themes of resource limitations; partnership parody; and lack of supervision.

"You know, in well-resourced countries, there is one-on-one supervision, or one-to-two, but here in South Africa we have large numbers of students with few supervisors". Vani believed that the shortage of staff and academic supervisors was a challenge facing South African clinical education.

Rod said, "So the point I am trying to make is that patient resources are extremely important, we cannot take them to places where they can't practice their skills or develop skills". He believed that the lack of exposure to clinical cases also impacts learning.

The partnership between the clinicians and academics was seen as imperative for optimal clinical education, according to most participants. Neville said, "For success (referring to DCT), we require clinicians and academics that are cohesive, not disagreeing“".

Simon also felt strongly about the value of this partnership and said: "OK, so the irony of it all is that the challenges we had were not at the CBPHCT sites but the urban sites".

Sam commented: "From former experience with clinicians, they are not the most willing participants in clinical education".

The relationship between the clinician at the clinical education sites and the student was believed to have an influence on the learning platform by all the academics.

Vani said, “... the staff (clinicians on site) can make this experience really enriching for our students, or they can really mess up our clinical education platform".

Neville also said, "The disadvantage is the lack of buy-in from the clinicians"; and Simon felt that, "The lack of interest from the leadership of the clinicians influences learning".

Sam agreed: "We've had situations where a physiotherapy department tells you straight up 'we don't want your students, they're a nuisance", and Rod felt that "the rural guys are very happy because they can delegate the work to the students. They can see other patients or have more time for other things that they need to do".

Some academic staff were ambivalent about the supervision offered by clinicians, compared to the previous system where predominantly academic clinical supervisors facilitated clinical education. Neville said, "The feelings of quality supervision, I still have a hard time accepting, because towards the end of the block in preparation for the final exam, I had to go in and do tutorials with the students".

Vani also added, "Whether the students are getting adequate supervision from clinicians with the new platform is still to be explored because we just don't know as yet".

The theme benefits of community-based clinical education included the sub-themes: personal growth for students; personal growth for academics; community as teachers; and pique research interest of clinicians.

Most academic participants felt that students showed growth and became independent following exposure to the DCT. This is reflected in Sam's quote: "I see that they are less needy. They are definitely more mature and more independent with DCT".

Zinhle also voiced her belief that: "advantages are that they are getting more than just a physiotherapy curriculum and they getting the life skills and that kind of stuff on becoming more rounded professionals".

Neville also said, “In terms of students' maturity, independence and neediness, I found the DCT certainly equipped 
us all better because we all have different teaching strategies and methods which is now evolving to a more student-centred approach".

Neville's quote reflects the personal growth of the academics as the academics are changing and allowing the students freedom to lead their own learning. Vani also felt like she had to learn to let students develop and become more independent. "I feel like I am too mothering and having students take charge like on this DCT platform, makes me want to change and improve my approach and be more enabling"(Vani).

The exposure to diverse communities as an enabler in clinical-based education is reflected in Selvan's belief: "Their backgrounds are, first of all, so diverse at DCT, which is great for students to develop". Simon felt: "The advantage is that they get out and see what's happening outside the urban setting".

Rod also commented that, "I think, for the first time, the students have proper exposure to communities and they are able to see the needs because they become one with the community and therefore really experience the community".

The academic staff also mentioned that the communities partner with the students as they learn during their clinical training. Neville believed, "we should also get buy-in from the community leaders, to make the experience even more enlightening for the students; where we meet with community leaders and we let them know that our students are in the area".

Zinhle also said: "Where there is a community-based rehabilitation programme, maybe our students can be involved in there so they can gain from the community".

The clinical education also benefited the clinicians who began to show an interest in furthering their studies and research. "I also think that it allows for this engagement with the students and them and it will stimulate areas of research for you as a professional physiotherapist" (Neville). Zinhle said, "The clinicians, having students around, want to learn more and are showing interest in pursuing research masters".

The final theme, recommendations for the learning platform, included the sub-themes: improved communication and collaboration; local clinical supervisors; and improved infrastructure.

Improved communication and collaboration encompassed the communication between various stakeholders. Tina felt that, "We need to look at offering a platform in order to improve the partnership between all stakeholders".

Neville alluded to the improved communication between the Department of Health and the university. "I would like to see that dual responsibility between the Department of Health and academia to benefit the students". Selvan said that, "Having the other professionals on board will help build on the experience".

Some of the academics felt that engaging local physiotherapists who are based in close proximity to the clinical sites would help with the learning experience. "Employ people to do clinical education from those areas" (Simon). "I've said it a few times now, that we should possibly be getting local therapists on board as part-time staff" (Zinhle).

The eight academics all agreed that improved infrastructure would facilitate learning on a DCT platform. "I think it's just the simple logistics that need to be improved, such as Wi-Fi; such as transport; when they need to do community projects; when they need to do home visits. In addition the accommodation, the environment where the students are going to be placed. I think the university needs to make sure that there's enough water, there's electricity and you know, those small things", said Simon. "I think it's the just the simple logistics that needs to be improved" (Selvan).

\section{Discussion}

The community-based primary healthcare approach to clinical education is vital for physiotherapy undergraduate training programmes as it aides in developing the traditional skills and core competencies required for independent practice (Ernstzen et al., 2014). Clinical learning placements are a platform to ensure that theory is put into practice (Chetty et al., 2018; Currens and Bithell, 2000). The participants in this study advocated for a student-led approach to clinical education. A study conducted by Sevenhuysen et al. (2014) on physiotherapy students in Australia, which aimed to assess the efficiency of peer-assisted learning frameworks, reflected that, even though peer-assisted learning reduced the workload of the clinical educator, the traditional approach of teacher-led learning was believed to be more favourable. This is in contrast to the findings in this paper, where academics believed that a shift to student-centred learning is imperative in the undergraduate curriculum. Physiotherapy academics also believed that the undergraduate curriculum needed to be reassessed, as gaps were identified, around the development of core competencies and social responsiveness of students. Chetty et al. (2018) agreed that there is a gap in clinical education for physiotherapists; and in their study in a similar context believed that the 
university competency framework was not emphasised in the undergraduate curriculum and that the health science student should demonstrate competence in the key roles as a 'practitioner, communicator, collaborator, leader, scholar, health advocate and professional'. Hartman et al. (2012) also believed that the curriculum should adopt the principles of primary healthcare, which are inclusiveness, participation and social responsiveness; and it should address the needs and interest of students, academics and the community. Crosbie et al. (2002) recommended that curriculum review should not merely be the addition of content but that irrelevant, stagnant curricula also need to be addressed.

Constraints to decentralised learning included inadequate resources, such as the shortage of staff in the healthcare sector in South Africa. This is echoed in other studies on decentralised learning approaches to clinical education for health science students (Woolleys et al., 2016; Caldwell and Aldous, 2017). A qualitative study carried out in the United Kingdom (Currens and Bithell, 2000) highlighted that supervising clinicians prioritised patient care over their role in clinical education. Clinicians also felt that students were a burden and they were not remunerated for the extra involvement in clinical supervision. Similar frustrations were evident in Talib et al.'s (2017) study, where it was noted that the increased number of medical students placed strain on the teaching hospitals, leading to a negative effect on the student-supervisor relationship. The poor partnership dynamics on the DCT platform also posed a barrier to learning. Milanese et al. (2013) emphasised that health institutions focus on providing quality care and the clinical education of the student may take a secondary role to patient management. The academics in this study highlighted the importance of team work between the supervising clinicians, students and academic staff from the university. Kibore et al. (2014), who conducted a study on decentralised training at the University of Nairobi in Kenya, mentioned the importance of close clinical mentorship in rural institutions in influencing students' clinical skills, which enhances the quality of patient care, and could further encourage the retention of health professionals within these healthcare facilities. This is in keeping with studies that emphasise the importance of a working collaboration between stakeholders for the success of clinical learning platforms (Gassner et al., 1999; Lo et al., 2017)

Academics who participated in the interviews in the current study felt that the benefits of community-based clinical education included both student and academic personal growth. Physiotherapy students were able to improvise and apply clinical reasoning with less supervised practice. Academics believed that students developed core competencies and seemed more independent in their approach to learning. Academics were able to shift their personal teaching strategy to a student-led approach. Exposure to diverse communities also enabled learning and equipped students with competencies to address healthcare needs in the South African contexts. According to Woollard (2014), decentralised clinical education is seen as a strategy to foster social accountability and can facilitate community empowerment. Supervising clinicians also benefitted and the placement of students at their facilities stimulated their interest in research and evidence-based practice. Community-based clinical education opens up avenues for future research ventures that may significantly benefit the community at large (Diab \& Flack, 2013). Furthermore, the academics who were interviewed at the university under study emphasised the importance of students learning from the community. The learning from the community enhanced community engagement and expanded knowledge and understanding of the community-based primary healthcare approach. Diab and Flack (2013) recognise that community leaders should also play a collaborative role in the learning platform as the primary focus should be the needs of the community. The students and the academics from the University of Nairobi who were involved in a similar decentralised clinical education platform shared the same sentiments, emphasising that this kind of clinical exposure to the community improves confidence in students, and inspires clinical and academic staff to gain from such exposure (Kibore et al., 2014).

In their recommendations for the learning platform, the physiotherapy academics participating in the study emphasised that improved collaboration through strengthened communication between stakeholders, such as academics and the local Department of Health, would enhance learning. Rodger et al. (2007) reported that a cohesive relationship between tertiary sectors and healthcare would aid in the accomplishment of shared goals that will facilitate improved patient access and care. Partnership is also crucial between the students and communities (Frantz and Smith, 2013), as this will enhance healthcare and healthcare education. Other recommendations included recruiting local clinical supervisors to facilitate learning during DCT placement (Moore et al., 2003). The physiotherapy department in this study is responsible for the process of recruiting part-time clinical supervisors. The recruitment process ensures that physiotherapists who are invested in the clinical learning platform are enlisted and engaged in the training of the undergraduate students. The improvement of resources available to students during DCT placement was also viewed as necessary for improving clinical education. Placing greater pressure on the university to improve telecommunications and access to online learning will facilitate learning on DCT platforms. 


\section{Conclusion}

This study sought to understand the perceptions of physiotherapy academics about the decentralised platform for clinical education of undergraduate students at a university in South Africa. The benefits of the community-based primary healthcare approach included the development of core competencies in undergraduate students, preparing them for independent practice; as well as a call for students to be more socially responsive as future healthcare practitioners. This study also suggests that the improved collaboration between stakeholders will curb opposition to the community-based learning platform.

\section{Competing Interests Statement}

The authors declare that there are no competing or potential conflicts of interest.

\section{References}

Caldwell, R. I., \& Aldous, C. (2017). The National Health Insurance, the decentralised clinical training platform, and specialist outreach. SAMJ: South African Medical Journal, 107(1), 39-40. https://doi.org/10.7196/SAMJ.2017.v107i1.12008

Chetty, V., Maddocks, S., Cobbing, S., Pefile, N., Govender, T., Shah, S., ... \& Mnguni, N. (2018). Physiotherapy clinical education at a South African university. African Journal of Health Professions Education, 10(1), 13-18. https://doi.org/10.7196/AJHPE.2018.v10i1.987

Creswell, J. W., \& Poth, C. N. (2017). Qualitative inquiry and research design: Choosing among five approaches (4th ed.). Thousand Oaks: SAGE Publications.

Crosbie, J., Gass, E., Jull, G., Morris, M., Rivett, D., Ruston, S., ... \& Wright, T. (2002). Sustainable undergraduate education and professional competency. https://doi.org/10.1016/S0004-9514(14)60276-2

Currens, J. A. B., \& Bithell, C. P. (2000). Clinical education: listening to different perspectives. Physiotherapy, 86(12), 645-653. https://doi.org/10.1016/S0031-9406(05)61302-8

Diab, P., \& Flack, P. (2013). Benefits of community-based education to the community in South African health science facilities. African Journal of Primary Health Care and Family Medicine, 5(1), 1-6. https://doi.org/10.4102/phcfm.v5i1.474

Elliott, R., \& Timulak, L. (2005). Descriptive and interpretive approaches to qualitative research. $A$ handbook of research methods for clinical and health psychology, 1(7), 147-159.

Ernstzen, D. V., Statham, S. B., \& Hanekom, S. D. (2014). Learning experiences of physiotherapy students during primary healthcare clinical placements: supplement 1-research. African Journal of Health Professions Education, 6(2), 211-216. https://doi.org/10.7196/ajhpe.530

Frantz, J. M., \& Smith, M. R. (2013). Exploring the subjective experiences of allied health professionals in their transition from clinical educators to academia: Barriers and facilitators to successful transition. African Journal of Health Professions Education, 5(1), 37-41. https://doi.org/10.7196/ajhpe.224

Gassner, L. A., Wotton, K., Clare, J., Hofmeyer, A., \& Buckman, J. (1999). Theory meets practice: Evaluation of a model of collaboration: academic and clinician partnership in the development and implementation teaching. Collegian, 6(3), 28. https://doi.org/10.1016/S1322-7696(08)60337-6

Govender, P., Chetty, V., Naidoo, D., \& Pefile, N. (2018). Integrated Decentralized Training for Health Professions Education at the University of KwaZulu-Natal, South Africa: Protocol for the I-DecT Project. JMIR research protocols, 7(1). https://doi.org/10.2196/resprot.7551

Hartman, N., Kathard, H., Perez, G., Reid, S., Irlam, J., Gunston, G., ... \& Van Rooyen, I. (2012). Health Sciences undergraduate education at the University of Cape Town: A story of transformation. SAMJ: South African Medical Journal, 102(6), 477-480. https://doi.org/10.7196/SAMJ.5680

Kautzky, K., \& Tollman, S. M. (2008). A perspective on Primary Health Care in South Africa: Primary Health Care: in context. South African Health Review, (1), 17-30.

Kibore, M. W., Daniels, J. A., Child, M. J., Nduati, R., Njiri, F. J., Kinuthia, R., ... \& Farquhar, C. (2014). Kenyan medical student and consultant experiences in a pilot decentralised training program at the University of Nairobi. Education for health (Abingdon, England), 27(2), 170. https://doi.org/10.4103/1357-6283.143778

Lo, K., Curtis, H., Keating, J. L., \& Bearman, M. (2017). Physiotherapy clinical educators' perceptions of student fitness to practise. BMC medical education, 17(1), 16. https://doi.org/10.1186/s12909-016-0847-2 
Longhurst, R. (2003). Semi-structured interviews and focus groups. Key methods in geography, 117-132.

Milanese, S., Gordon, S., \& Pellatt, A. (2013). Undergraduate physiotherapy student perceptions of teaching and learning activities associated with clinical education. Physical Therapy Reviews, 18(6), 439-444. https://doi.org/10.1179/1743288X12Y.0000000060

Moore, A., Morris, J., Crouch, V., \& Martin, M. (2003). Evaluation of physiotherapy clinical educational models: comparing 1: 1, 2: 1 and 3: 1 placements. Physiotherapy, 89(8), 489-501. https://doi.org/10.1016/S0031-9406(05)60007-7

Paliadelis, P. S., Parmenter, G., Parker, V., Giles, M., \& Higgins, I. (2012). The challenges confronting clinicians in rural acute care settings: a participatory research project. Rural Remote Health, 12(2), 1-12.

Panda, B., \& Thakur, H. P. (2016). Decentralization and health system performance-a focused review of dimensions, difficulties, and derivatives in India. BMC health services research, 16(6), 561. https://doi.org/10.1186/s12913-016-1784-9

Rodger, S., Webb, G., Devitt, L., Gilbert, J., Wrightson, P., \& McMeeken, J. (2008). Clinical education and practice placements in the allied health professions: an international perspective. Journal of Allied Health, 37(1), 53-62.

Sevenhuysen, S., Skinner, E. H., Farlie, M. K., Raitman, L., Nickson, W., Keating, J. L., ... \& Haines, T. P. (2014). Educators and students prefer traditional clinical education to a peer-assisted learning model, despite similar student performance outcomes: a randomised trial. Journal of physiotherapy, 60(4), 209-216.

South African Government. The National Health Insurance White paper, 2015 (www.gov.za/sites/www.gov.za/files/nationalhealthinsurance. White paper)

Talib, Z., van Schalkwyk S., Couper, I., Pattanaik, S., Turay, K., Sagay, A. S., ... \& Kibore M. (2017). Medical Education in Decentralized Settings: How Medical Students Contribute to Health Care in 10 Sub-Saharan African Countries. Academic Medicine, 92(12), 1723-32. https://doi.org/10.1097/ACM.0000000000002003

Wilson, N., Couper, I., De Vries, E., Reid, S., Fish, T., \& Marais, B. (2009). Inequitable distribution of healthcare professionals to rural and remote areas. Rural Remote Health, 9, 1060.

Woollard, R. F. (2014). From the village to the globe: the social accountability of rural health practitioners. WONCA Rural Medical Education guidebook, Chapter 1.1.3.

\section{Copyrights}

Copyright for this article is retained by the author(s), with first publication rights granted to the journal.

This is an open-access article distributed under the terms and conditions of the Creative Commons Attribution license (http://creativecommons.org/licenses/by/4.0/). 